\title{
Professional Development via Facebook Group: Perception of School Librarians
}

\author{
Zakir Hossain \\ European International School, Ho Chi Minh City, Vietnam
}

\begin{abstract}
Facebook offers the ability to its users to create a group on a specific subject or interest and ask friends and acquaintances to join and share information which is entirely driven by them. This study seeks to explore whether and how Facebook group adds value to the complex process of school librarians' professional development. The successive objectives are to understand the current and future professional learning trends in school librarianship through Facebook group posts. An online questionnaire was posted to selected Facebook groups and sent to two school librarians' listservs, and 404 usable responses were received. Study findings indicate that with the Facebook group, School Library Professionals (SLPs) are able to stay informed with new knowledge in their field by exchanging information, opportunities and ideas. The findings also confirm that more and more SLPs are using, or at the very least, experiencing Facebook groups as a Professional Development Tool (PDT). Study data shows that 78.4 percent of SLPs desire to see posts related to 'teaching resources' and 63.8 percent 'how to use technology' on the Facebook group and are also indicative of the current professional learning trends of SLPs. Research skills tips $(67.9 \%)$, makerspace ideas $(57 \%)$ and how to collaborate with classroom teachers $(51.6 \%)$ are found to be the top future professional learning aspirations of SLPs. This paper provides valid empirical evidence and highlights that many SLPs are using Facebook groups and 38.4 percent regarded it as a 'very useful tool' for professional development. The discussions that take place on Facebook groups empower and enhance librarians' professional practice and networking.
\end{abstract}

\section{Keywords: School Librarian, Facebook Group, Social Media, Professional Development, Librarianship}

\section{INTRODUCTION}

Professional development (PD) is considered to be the primary mechanism of continuous learning and improvement of skills of an employee over time. According to ACRL (2000) "professional development is an important manifestation of the academic librarian's commitment to personal excellence". Today, the Internet offers librarians vast opportunities in diverse areas through social media which enables interaction among librarians worldwide for personalized learning and PD. Social media such as Facebook is increasingly embedded in many areas of life as a powerful platform for discussion, entertainment, communication, news, advertisement and professional development. More and more people use Facebook because of its customizable features for those things people want to see. Just half a decade ago, people look at Facebook as a more personable network, where one could share stories, pictures, and posts with friends and family. In recent years, however, there has been a sea-change in approaches.

Today's Facebook encompasses a range of tools, formats, and contexts for its platform is seen by many as a Learning Management System (LMS) and informal yet effective medium for PD or at least for professional networking (Wang et al., 2012; Manca and Ranieri, 2013 and Ballantyne, Lowe \& Beddoe, 2017). There is plenty of PD information being shared by individuals and organizations on Facebook where both larger and smaller groups of people gather, discuss common concerns, initiate informal learning environments designed and entirely driven by them (Wassen, 2016). 
The remarkable development and popularity of Facebook-based interactions have affected school library professionals too, who often feel professionally isolated but now utilize different aspects of Facebook such as Facebook page and Facebook group to fulfill a variety of objectives from library marketing and outreach to professional development and networking. According to ACRL (2000), librarians should aggressively seek opportunities to learn from a variety of sources in related professions and in professions that have not traditionally been associated with libraries". In this case, Facebook group is considered as a very useful PDT as it has boundless opportunities for members and followers to learn while also contributing to the knowledge of others across their online communities (Curtis, 2011).

Lately, Facebook group is considered an educational tool and Chen (2014) claims that Facebook group can even be used as a Learning Management System (LMS) substitute or as a supplemental tool. Members and followers of Facebook groups are, therefore, exposed to an ever greater variety of viewpoints and ways of looking at the world. Since the tools are already available and mostly free, and librarians are encouraged to leverage these tools for their PD and networking in the technological age with the only investment of time.

\section{STATEMENT OF THE PROBLEM}

Since 2006, social media has steadily gained acceptance among libraries and librarians for professional reasons (Graham et al., 2009 and Hendrix et al., 2009). As librarians' practice advance within the framework of community, social media moves from a one-dimensional online broadcast platform to a multidimensional, socially-connected space that creates value for both the library and library professionals (Young and Rossman, 2015). In an ever-changing world where skills often become outdated, there is a need for re-learning in order to cope with new challenges. As Onuoha (2013) stated, like other professionals, librarians develop themselves professionally through conferences, seminars, workshops etc.

The use of social media, mainly Facebook by libraries and librarians to engage with patrons and PD, has gained tremendous attention (Hagman \& Caleton, 2014; Ramsay \& Vecchione, 2014). Most recent discussions by Simons et al. (2016), Onuoha (2013) and Kukreja et al. (2011) about social media for PD focus on Facebook rather than other on social media platforms, but little is known about how library professionals actually learn using Facebook page and Facebook group in a PD context (Simons et al., 2016).

Though, library professionals may not all settle on social media being useful for professional purposes, a few studies were conducted to report on Facebook adoption and librarians' perception of this new tool (Charnigo and Barnett-Ellis, 2007). Regardless of the potential challenges, Facebook group may provide an excellent opportunity for librarians to increase communication regarding professional practice issues but to what extent do librarians avail themselves of these Facebook applications remains unknown (Onuoha, 2013) due to limited published data.

\section{OBJECTIVE OF THE STUDY}

Facebook group offered librarians different possibilities and studies indicate that a both wider and deeper understanding of the role of Facebook and Facebook group in librarianship is necessary in order to determine its effect as an informal PDT (Ayu \& Abrizah, 2011 and Vassilakaki \& Garoufallou, 2015). To date, little empirical research on the professional use of Facebook group has been conducted, particularly with reference of SLPs on the Facebook group. The present study was formulated to define school librarians' use of Facebook namely Facebook groups as a PDT in a global context. It is expected that the results from this study will be a pioneer upon which prospective studies may be anchored.

To achieve this objective, along with exploring the broad nature of the Facebook group, this study addresses the following key questions:

1. What role Facebook group plays as a PDT and to what extent?

2. What are the challenges in following the Facebook group?

3. What are the current and future PD aspirations of SLPs? 


\section{REVIEW OF RESOURCES}

Social media such as Facebook provides greater control in communication and collaboration over both the degree of privacy and size of a group when compared with previous forms of communications media. Cultural institutions such as libraries, community learning centers, archives and museums are increasingly using various forms of social media tools not just to promote their services, but to engage their professional communities through outreach wherever they are based, and however they choose to learn (Hossain, 2016; McCallum, 2014). Social media, therefore, has been changing the way organizations and individuals view their personal lives and their professions.

According to Meyrowitz (1997), individuals no longer required to travel and "be" in a physical location to collect information or participate in discussions nor have to be excluded themselves from the events they cannot physically present. Online social media develops the flow of information hence individuals in virtual networks gain information about opportunities and choices that otherwise would not be available to them (Lin, 2002). This has been made possible through different forms of social media that enable interaction in virtual space without the constraints of time and location.

Similarly, there are reports of studies related to the use of social media or social networking sites by librarian and libraries. Chu and $\mathrm{Du}$ (2013) and McCallum (2014) for example investigated the use of social networking tools in academic libraries, librarians perceptions, usefulness and challenges, and factors influencing decisions to use or not to use such social media tools. Dickson and Holley (2010) delved into the use of the major social networking tools in academic libraries in the United States and found that social networking can be an effective method of community outreach in academic libraries. Based on the findings of Onuoha's (2013) study, librarians in Nigeria actively seek means of PD using social media and recommends, among others, the active use of social media tools to contribute to professional learning and professional development. Simons et al. (2016) even go further in suggesting developing coursework and teaching social media practice in library science programs: MLIS and MSIS.

As social media has grown and become part of almost every aspect of our lives, the use of it for professional development is not a modern day phenomenon (Onuoha, 2013) only the demand on time due to the advancement of technology, popularity and user-friendly platforms. Facebook, for example, is not only used for social connections around the world but also for PD and so much of the academic work on this topic has become integrated into different disciplines (Vassilakaki and Garoufallou, 2015).

Gruber (2008) states that as a result of using Facebook, librarians most likely increase their expertise and gain advice on issues that arise in their professional work and are updated on what is going to be the next set of essential skills for their profession. Majid's (2004) statement echoes Gruber's (2008) rationale that the purpose of continuing professional development activities is to fill in the knowledge gaps between formal education and the needs of the professional practice.

Many studies such as Breeding (2007) listed the reasons that Facebook could be important to libraries. Ranieri, Manca and Fini (2012) explored the professional use of Facebook and its implications for lifelong learning and the way educators engage in it. Facebook was also recommended as a way for librarians to share information (Mathews, 2006) and to learn about new developments (Parveen, 2011). In addition, Roncaglia (2007) stressed the educational aspects of Facebook for exchanging information, especially for school libraries.

Results from a Karal and colleagues (2015) study indicate that Facebook groups create a flexible online community with interactive and reflective activities, and are an effective tool for sharing ideas, and for communication and cooperation amongst group members. Survey findings by Ballantyne, Lowe \& Beddoe (2017) concluded that participants highly valued Facebook group for its ability to post and share information, and to access professional news within communities of practice. These examples demonstrate that library professionals appear to consider it useful to use Facebook group and are, at the very least, experimenting with it for professional development and networking.

Vassilakaki and Garoufallou (2015) went further providing the baseline for creating a series of best practices for librarians' use of Facebook group for professional purposes successfully. Most people may prefer Facebook groups to Facebook pages as McKenzie (2016) said groups are more interactive and 
can have a proper conversation, where every member can post, which means much more diversity and less work for the moderators in what is posted. Some groups are closed, and some are open depending on how members feel about others' posts being accessible on the wider web and obviously, they need to consider which group is right for their intended purposes.

According to a claim by Emery (2008), librarians who follow professional groups and pages on Facebook are most likely to identify what their colleagues in other institutions are focusing on which can be localized more readily to their own work without reinventing the wheel. In other words, experiences can be shared at the local level that are gained from colleagues at an international level, which then feed into service development at a local level and vice-versa. Indeed, Oberg (2002) notes that without new experiences, we tend to stagnate and become brittle. Choi (2012) goes further and urged libraries and librarians to be prepared for the social media librarian.

Emery (2008) and Choi's (2012) statements are justified by McCallum (2014) findings that over $70 \%$ of libraries are using social media tools, and $60 \%$ have had a social media account for three years or longer and $30 \%$ of librarians are posting at least daily. Findings from Onuoha's (2013) study revealed that online social networks such as Facebook and Wikis were mostly used for PD where librarians learn mostly by reading through the conversations of others and joining discussion groups. However, professional competencies today may not be so essential or useful tomorrow, hence a need for professional learning throughout. Holmes (2012) argued that as many professionals still feel highly uncertain about their work skills, and so social media such as Facebook group would be an interesting yet effective professional learning and networking venue for both experienced and inexperienced professionals.

\section{METHODOLOGY}

This study embraces a descriptive approach mainly because it was an exploratory study and no local or international studies could be traced on the topic. The population for this study was school library professionals worldwide.

There are literally hundreds of Facebook groups that focus on librarianship in general of which some exclusively concentrate on school librarianship. The researcher, from his own understanding, listed 10 exclusive Facebook groups (see chart 5) with an extra option, that is 'Other' to understand the scenario of popular Facebook groups participating by SLPs. Within the 10 Facebook groups, only ALA Think Tank is considered a general group. Nearly at the end of the survey, the researcher came to learn of another popular Facebook group namely 'Future Ready Librarians' and added that to the list. Selections were made from a number of followers/members, likes, posts, comments in a Facebook group. The survey instrument was developed based on the research questions using the researcher's own knowledge titled "Role of Facebook Group in School Librarians' Professional Development" using Google Form. The instrument was pretested on five SLPs and changes were made based on their comments and suggestions.

The actual questionnaire link posted on selected Facebook groups and the listservs in early August 2016 and several follow-up posts were posted. The responses were automatically recorded and tabulated on Google Form and analyzed. Some respondents did not answer all questions, and the missing responses are reflected in the varying sample size $(n)$ values in the findings below.

\section{Background of Respondents}

\section{RESULTS}

A total of 404 responses were received of which 366 (91.7\%) identified as females, $29(7.3 \%)$ males and $4(1 \%)$ participants preferred not to disclose their gender. The age group of 'more than 50 years' had the highest number of respondents (36.7\%), following the age group of '46-50 years' (18.9\%) while the age group of '21-25 years' or younger had the least number of respondents $(1.7 \%)$. Data from this study confirmed that school libraries are overwhelmingly dominated by female library professionals and a good number of them are over 50 years old. These results are attested by the earlier finding by 
Beveridge and colleagues (2011) that the current makeup of the library profession in the US is $83 \%$ female where 64 percent of them 45 years or older.

The respondents' demographic information also revealed the respondents' years of working experience in librarianship. Their length of service as a school library professional was $25.6 \%$ 'more than 5 years ', 18.9\% 'more than 10 years', 19.2\% 'more than 20 years' and $14.2 \%$ 'more than 15 years' and 'less than 3 years'.

In terms of qualifications, $68.7 \%$ have a master's degree, $14.9 \%$ have a bachelor's degree and 3.7\% holds a Ph.D. degree. 81.4\% indicated they have the degree in Library and Information Science (LIS) or related discipline and $13.4 \%$, however, indicated that their highest academic qualification was in other disciplines and 5.2\% mentioned they are currently enrolled in an MLIS program.

The majority of the respondents are working for public (55.8\%) libraries followed by international and private school libraries in 57 different countries $(n=401)$ with the highest number of participants from the USA (60\%), followed by Australia (8\%), Indonesia (6\%) and Vietnam (5\%). Chart 1 shows the distribution of the respondents' work sectors. Individual data analysis shows that $23 \%$ of survey participants recorded their working places in 53 different countries which covered all major geographic regions throughout the world.

Chart 1: Respondents' work sectors $(n=403)$.

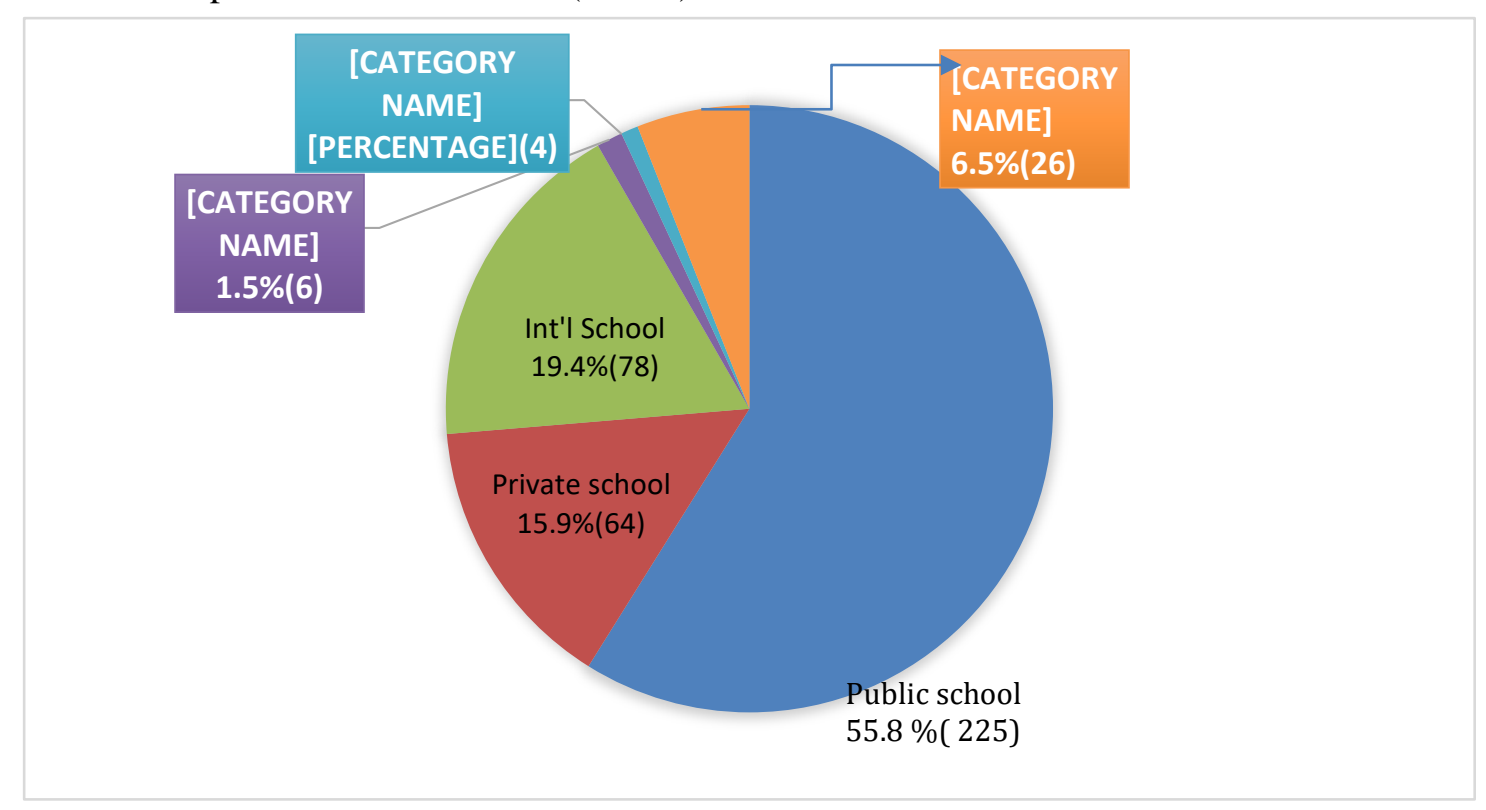

Participants' job titles are very versatile from place to place within and outside of a country or region. Further data analysis revealed that respondents mentioned 23 different job titles where most of the participants use the titles' Librarian (25\%) followed by School Librarian (21\%) adding ranges of prefixes such as Elementary, Middle, High/Secondary, Senior/Junior School Librarian etc. 5\% of respondents were professor, lecturer, library consultant and researcher whereas $14 \%$ (54) participants mentioned different job titles other than listed in chart 2. In-depth data analysis confirmed that SLPs in the USA widely use School Library Media Specialist as their job titles whereas SLPs in Australia and in international schools use Teacher-Librarian as their job titles with some dissimilarities.

Chart 2: Top five job titles of SLPs worldwide $(n=370)$ 


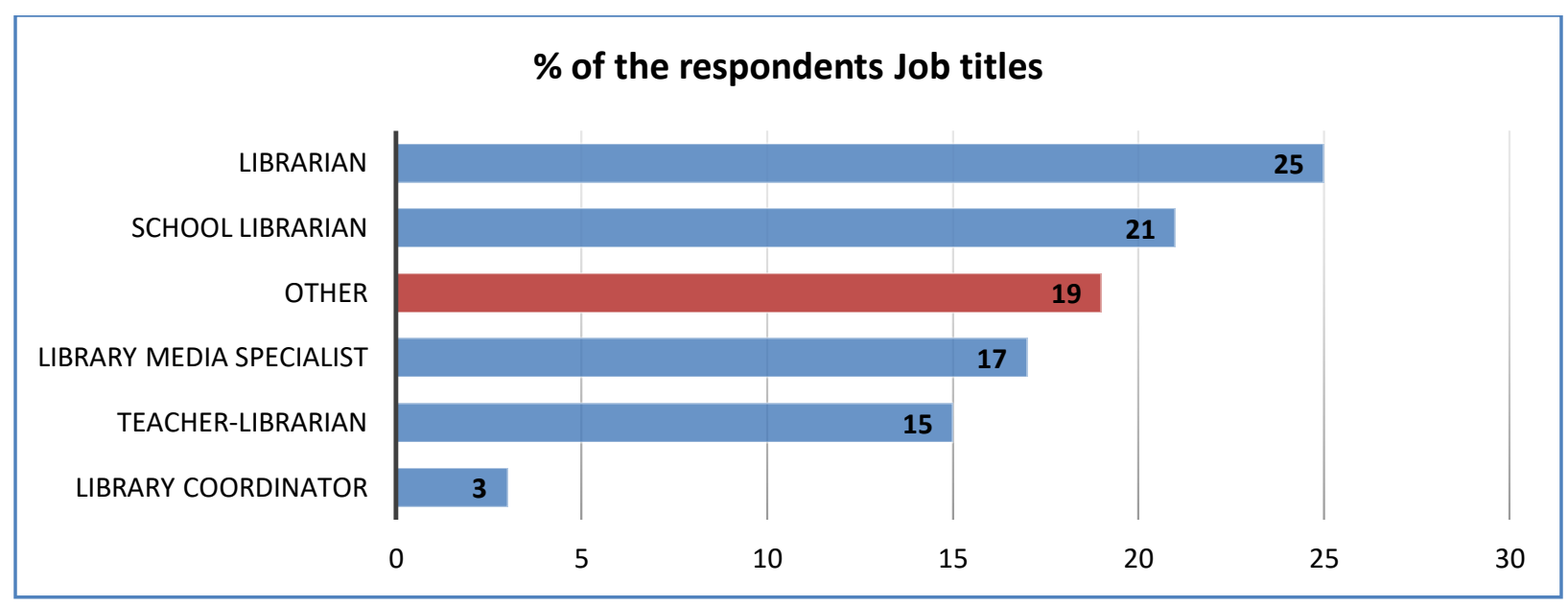

\section{Summary of Findings}

Study findings indicate that a vast majority $(89.1 \%)$ of SLPs use social media such as Facebook (73.6\%), Twitter (51.1\%), Blogs (43.4\%) and Pinterest $(33.7 \%)$ for their continuous professional development (CPD). This study also revealed that 53.8\% of respondent SLPs have been using Facebook for more than seven years, $47.5 \%$ follow one to three professional groups and $54.9 \%$ spend one to two hours per week for PD on Facebook. A number of SLP respondents (38.4\%) rated Facebook groups as a 'very useful tool' to develop their professional learning and $40.2 \%$ regarded it as a platform that empowers and enhances their professional practice and networking.

Despite the growing popularity of Facebook and Facebook groups across multiple disciplines, study analysis shows that $12.2 \%$ of SLP survey participants were not willing to use these venues in professional practice. The main challenges they face are the lack of time $(56.2 \%)$ and the overwhelming number of posts $(43.8 \%)$ to read and explore.

However, the present study result implies that more and more SLPs are using, or at the very least, experiencing Facebook and Facebook groups as a PDT in comparison to earlier studies. For example, a 2015 study by McKenzie (2015) found that $97 \%$ of respondents $(n=78)$ school librarians used Facebook and other social media only for personal use which was far more than the current study. Roughly three-quarters $(78.4 \%)$ of survey participants prefer to see the posts related to teaching resources, $63.8 \%$ and $63.2 \%$ desire to see 'how to use technology' and professional seminar and conference news respectively which imply the current professional learning trends of SLPs. Research skills tips and resources $(67.9 \%)$, makerspace ideas $(57 \%)$ and how to cooperate and collaborate with classroom teachers $(51.6 \%)$ are found to be the top future professional learning aspirations of SLPs.

Overall, respondents' feedback confirmed that with the Facebook group, school librarians are able to stay informed with new knowledge in their field. In terms of PD, it was indicated that Facebook group provide the opportunity for sharing knowledge, and serve as a source of educational and professional information, sharing common interests or affiliations, upload and stream live videos, hold discussions in forums, and allow professionals to exchange information, opportunities, and ideas. As a result of this, it was indicated they have the opportunity of creating a forum comprising like-minded librarians who share common interests and benefits. This is also in-line with the observation by Suraweere et al. (2011) that there are sites such as the Facebook group that help professionals to network and build relationships among themselves.

\section{Ways SLPs Keep Up To Date Professionally \\ ANALYSIS AND DISCUSSION}

Respondents' data analysis explored in more detail how SLPs are kept up-to-date professionally. Not surprisingly a vast majority (89.1\%) of the SLPs use 'Social media groups' to keep up-to-date professionally. Results show that attending professional conferences and training $(84.9 \%)$ is equally 
important as social media groups but participation in such are not always free. Free online webinars and Massive Open Online Courses or MOOCs $(64.1 \%)$ are also becoming popular among SLPs in order to be professionally sound. Chart 3 lays out key methods of SLPs' ways to stay abreast professionally.

Chart 3: Top Five ways School Librarians keep up-to-date professionally $(n=404)$

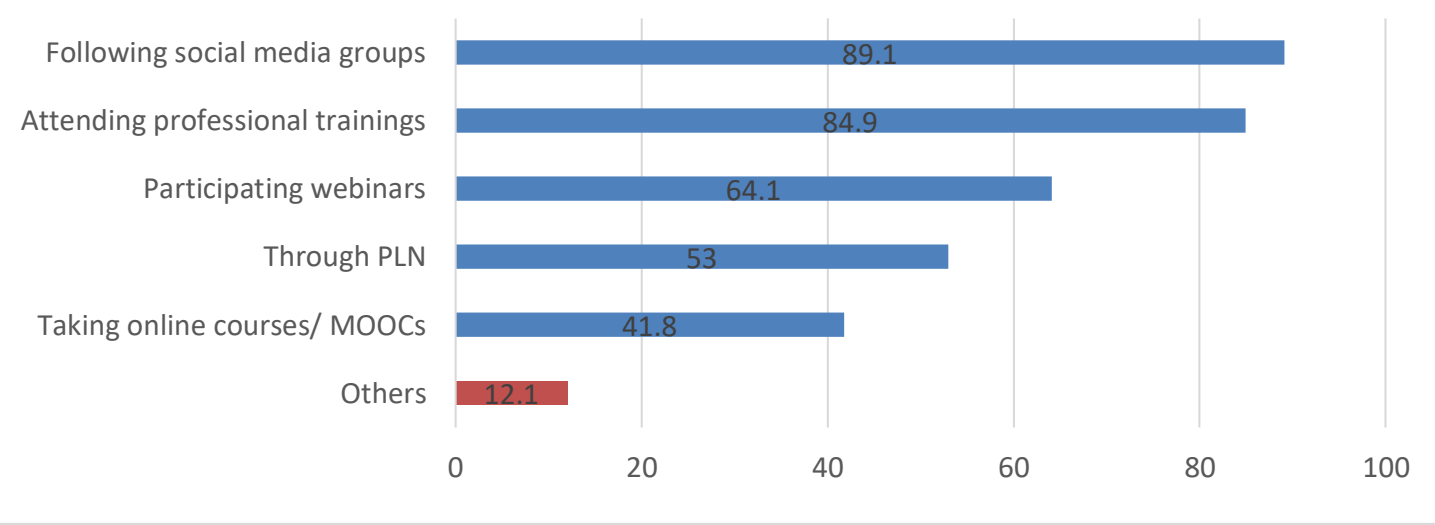

\section{Top Five Social Media SLPs Use for PD}

When asked what social media platforms participants prefer for PD, the majority of SLPs replied Facebook (73.6\%) followed by Twitter (51.1\%) and Blogs (43.3\%). Graph 2 illustrates SLPs' preferred social media platforms for PD.

Chart 4: Top Five social media SLPs use for PD $(n=401)$

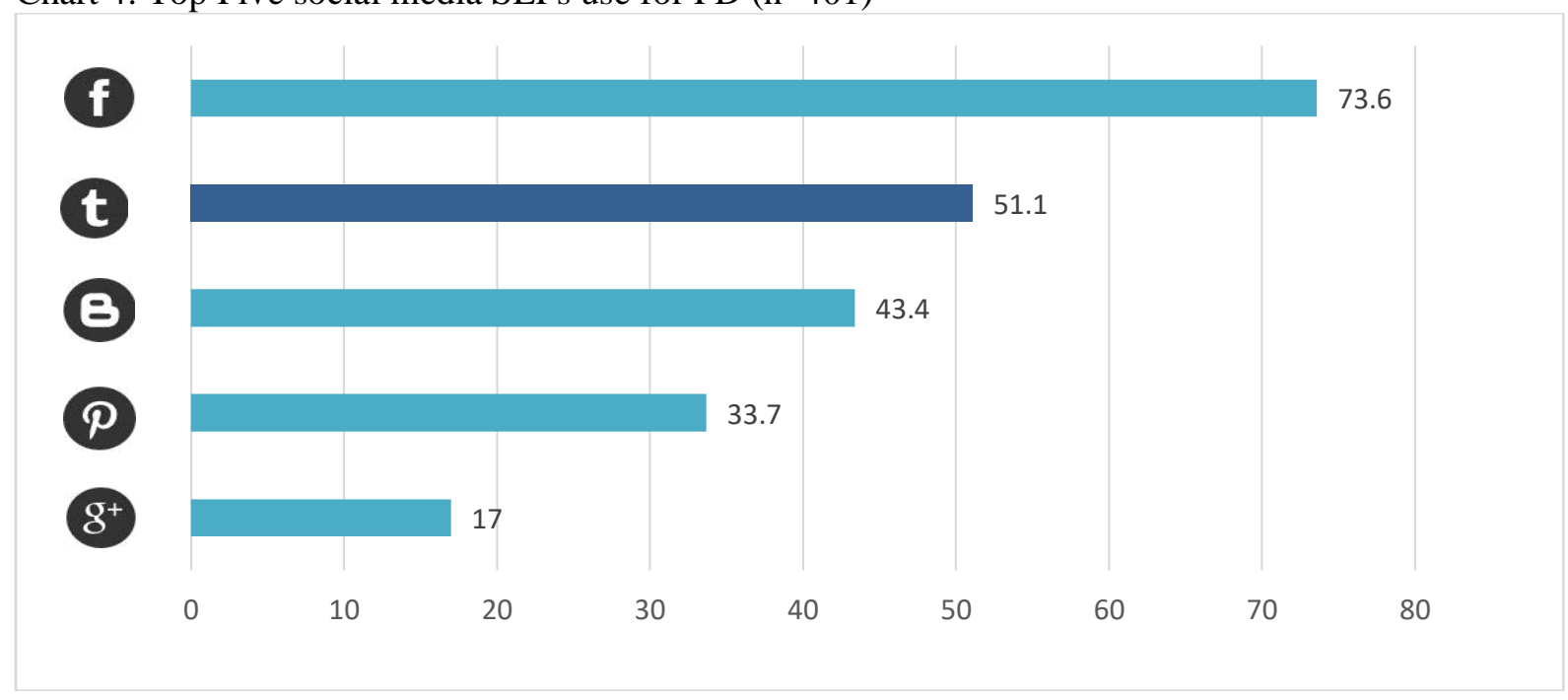

This study's findings are harmonious with the reports of Simon (2016), and Chu and Du (2012) who reported that Facebook and Twitter were the most commonly adopted social media platforms by academic libraries and librarians for professional development and networking.

\section{SLPs Familiarity with Facebook}

Among the 403 respondents, 53.8\% SLPs has been using Facebook for more than 7 years and shockingly $12.2 \%$ aren't using Facebook let alone Facebook group. Table 1 shows the detailed scenario.

Table 1: SLPs familiarity with Facebook 


\begin{tabular}{|l|c|c|}
\hline Years of familiarity with Facebook & $\mathbf{n = 4 0 3}$ & $\%$ \\
\hline $1--2$ & 25 & 6.2 \\
\hline $3--4$ & 44 & 10.9 \\
\hline $5--6$ & 68 & 16.9 \\
\hline More than 7 & 217 & 53.8 \\
\hline I don't use Facebook & 49 & 12.2 \\
\hline
\end{tabular}

\section{Number of Facebook Group (S) SLPs Follow/Members}

Results show that most of the respondents follow more than one professional Facebook group and surprisingly $8.6 \%$ said they have been members/followers of more than 10 professional Facebook groups, depicted in table 2 .

Table 2: Number of professional Facebook group(s) participants follow on Facebook

\begin{tabular}{|l|r|r|}
\hline Number of Facebook group(s) & $\mathbf{n = 3 6 0}$ & $\%$ \\
\hline $1--3$ & 171 & 47.5 \\
\hline $4--6$ & 128 & 35.6 \\
\hline $7--9$ & 30 & 8.3 \\
\hline More than 10 & 31 & 8.6 \\
\hline
\end{tabular}

\section{SLPs Favourite Facebook group(s) for Professional Development}

To explore SLPs preferred Facebook group(s), a list of group names were given and remarkably, $46.2 \%$ - the highest number of respondents selected 'other' meaning they follow the groups that do not fall within the listed groups shown in Chart 5. The results also confirmed that there are many other Facebook groups that SLPs are using as their informal PDT.

Chart 5: SLPs favourite Facebook group(s) for PD purpose $(n=358)$

THE SCHOOL LIBRARIAN'S WORKSHOP

OTHER

AASL (USA)

ALA THINK TANK*

INT'L SCHOOL LIBRARY CONNECTION

SCHOOL LIBRARIANS/LIBRARY TECHNICIANS

INTERNATIONAL LIBRARIANS NETWORK (ILN)

FUTURE READY LIBRARIANS

ASLA (AUSTRALIA)

SLA (UK)

VIETLIB (VIETNAM)

OLA (CANADA)

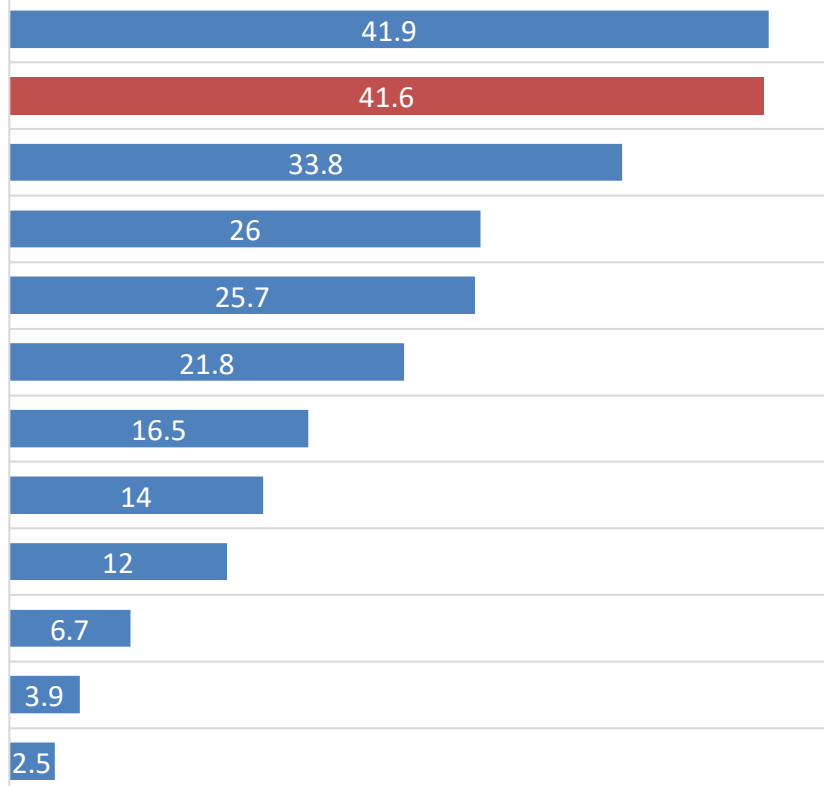




\section{Frequency of Facebook $(n=348)$ and Facebook groups $(n=357)$ usage by SLPs}

A resounding 185 (50.4) out of the 367 respondents indicated that they use Facebook several times a day. Regarding Facebook groups' usage, $12 \%$ of respondents use it 'more than once a day' and $29.1 \%$ use it 'at least once a day' for professional development purposes. Table 3 shows the frequency of Facebook and Facebook group usage by the survey participants.

Table 3: Frequency of Facebook and Facebook group usage by SLPs

\begin{tabular}{|l|l|l|}
\hline Frequency & \% of Facebook usage & \% of Facebook group(s) usage \\
\hline More than once a day & 50.4 & 12 \\
\hline At least once a day & 31.9 & 29.1 \\
\hline 2-3 times a week & 7.9 & 24.4 \\
\hline At least once a week & -- & 10.4 \\
\hline Every few weeks & 4.9 & 09 \\
\hline $\begin{array}{l}\text { 24/7 (always login)/Whenever a post } \\
\text { appeared }\end{array}$ & 4.9 & 15.2 \\
\hline
\end{tabular}

Further analysis shows that in a typical week, 54.9\% respondent SLPs spent one to two and $11.5 \%$ spent three to four hours respectively on Facebook group(s) for PD purposes. A number of the respondents $(29.9 \%)$ indicate that they are frequent viewers meaning that they view each post after it appears on their feeds. Respondents who reported using Facebook multiple times a day were more likely to use it for professional purposes than personal ones. These results also indicate that SLPs are using Facebook groups on a daily basis and partially on a weekly basis.

\section{What SLPs Prefer To See On Facebook Group(S) They Follow $(n=356)$ ?}

Roughly three-quarters $(78.4 \%)$ of the survey participants shared they prefer to see the posts related to 'teaching resources' following 'book/genre lists and recommendations' (71.5\%) for specific age and user groups portrayed on chart 6 . Interestingly, $31.1 \%$ of respondents desire to see related 'job vacancies' on Facebook groups they follow. All these preferences clearly imply the current professional development trends of SLPs.

Chart 6: SLPs desired posts on the Facebook group(s) of which they are members or followers. 


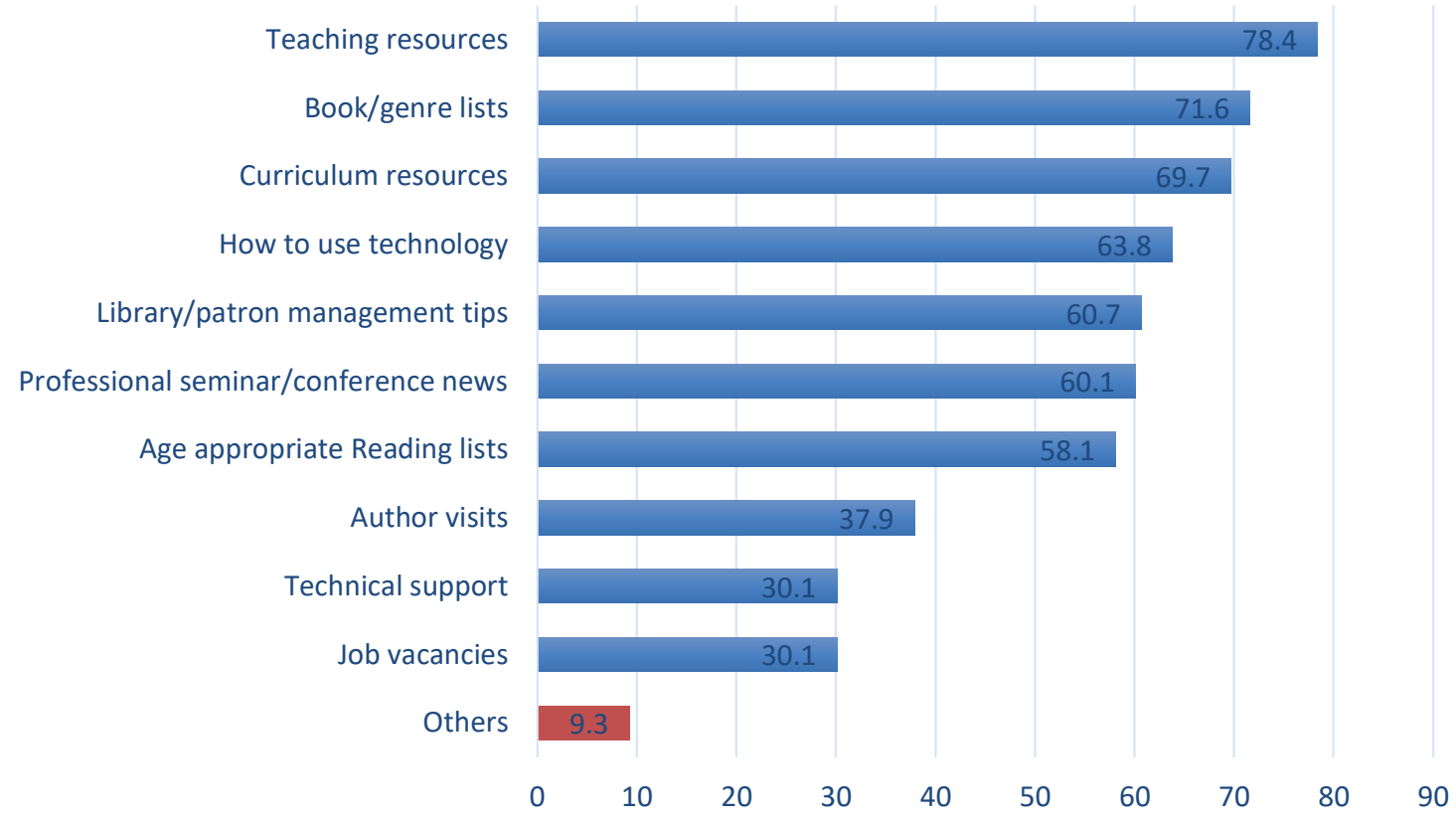

\section{To Which Posts Are SIps Most Likely To Respond E.G. Like/Comment/Share $(n=362)$ ?}

Participants were asked if they were to read a group of Facebook posts, which topics would they most likely respond to, that is like, comment or share. Table 4 demonstrates the scenario.

Table 4: Popular posts to SLPs

\begin{tabular}{|l|c|c|}
\hline Posts & $\mathbf{n = 3 6 2}$ & \% \\
\hline Job posts & 36 & 09.9 \\
\hline $\begin{array}{l}\text { Incredible works by other } \\
\text { librarians }\end{array}$ & 260 & 71.8 \\
\hline Advocacy by other librarians & 209 & 57.7 \\
\hline Reading list & 155 & 42.8 \\
\hline Book/genre list & 170 & 47 \\
\hline New technology & 195 & 53.9 \\
\hline Useful apps & 206 & 56.9 \\
\hline $\begin{array}{l}\text { Library software technical } \\
\text { support }\end{array}$ & 72 & 19.9 \\
\hline Teaching resources & 239 & 66 \\
\hline Library/patron management tips & 142 & 39.2 \\
\hline Author visits & 73 & 20.2 \\
\hline
\end{tabular}

Comfortability of Like, Comment or Share a Post on the Facebook Group ( $n=362)$

40.6 percent of survey participants agreed that being a member of a Facebook group they feel very comfortable to like, comment or share posts on their Facebook groups. Table 5 illustrates their comfortability on a Likert scale of $1-5$ where 1 is 'very comfortable' and 5 is 'very uncomfortable'. 
Table 5: Comfortability of like, comment or share a Facebook group post

\begin{tabular}{|r|c|c|}
\hline \multicolumn{1}{|l|}{ Feelings } & $\mathbf{n = 3 6 2}$ & \% \\
\hline Very comfortable: 1 & 147 & 40.6 \\
\hline 2 & 105 & 29 \\
\hline 3 & 88 & 24.3 \\
\hline 4 & 16 & 4.4 \\
\hline Very uncomfortable: 5 & 6 & 1.7 \\
\hline
\end{tabular}

\section{Facebook Group as a Professional Development Platform ( $n=365)$}

Not surprisingly many SLPs (29\%) rated Facebook group as an 'Excellent' tool for professional development or networking. Table 6 identified respondents rating of Facebook groups as a professional learning tool on a Likert Scale of 'Excellent' to 'Very poor'.

Table 6: Facebook group as professional development platform rated by SLPs

\begin{tabular}{|l|c|c|}
\hline Effectiveness & $\mathbf{n = 3 6 5}$ & $\%$ \\
\hline Excellent : 1 & 106 & 29 \\
\hline 2 & 140 & 38.4 \\
\hline 3 & 84 & 23 \\
\hline 4 & 22 & 6 \\
\hline Very poor: 5 & 13 & 6.3 \\
\hline
\end{tabular}

\section{Frequency of Post on a Facebook Group $(n=360)$}

$64.7 \%$ of respondents shared that they post on their Facebook group(s) whenever they feel it necessary while $14.2 \%$ never post on the group(s) they followed. Graph 1 shows respondents' frequency of post(s) on the Facebook group of which they are a member or follower.

Graph 1: Frequency of Facebook group post(s) as a member or follower

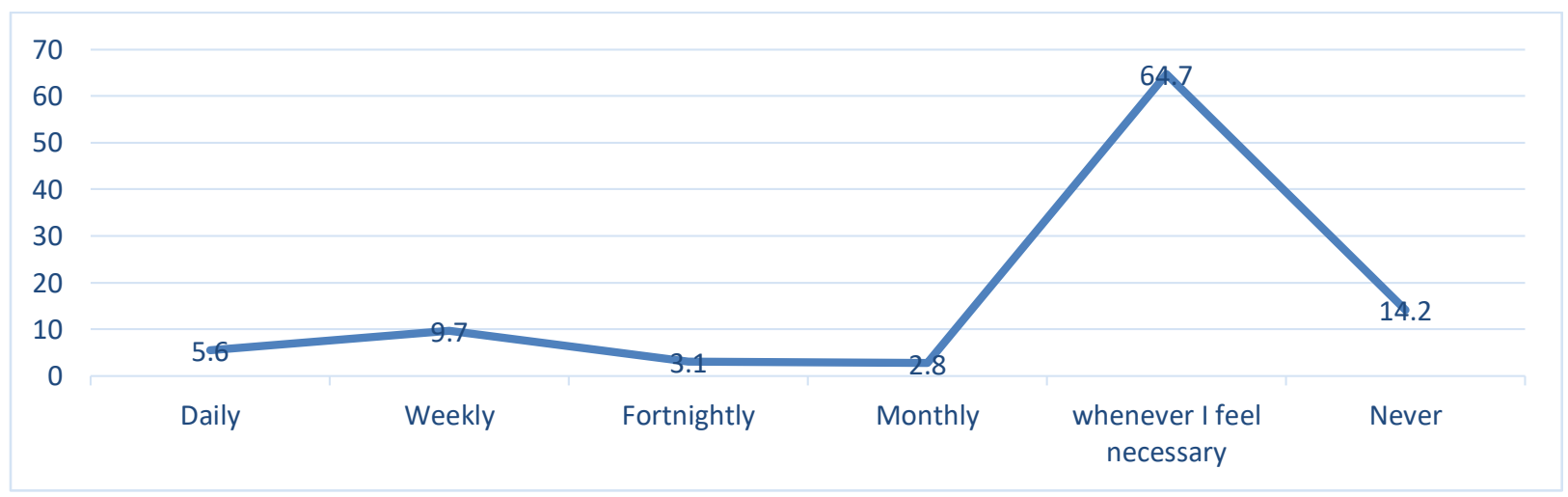




\section{Benefits of Being a Facebook Group Member or Follower $(n=206)$}

To determine the importance of becoming a member or a follower of a Facebook group and the benefits SLPs derived from making use of it, participants were asked to share their personal thoughts (in written form) on the benefits of participating in a professional Facebook group. Respondents listed the benefits include the ease with which to share ideas, the discovery of library values, access to like-minded professionals who offer support and collegiality that may not be available in face-to-face working environments. On the use for personal development, the respondents indicated that they have the opportunity to connect with people across the globe including those that have never seen and which they are not sure of coming in contact with face to face. 


\section{Selected SLPs Voices}

* Facebook is an easy platform to use - no formal letter writing, just sharing

Being able to get timely info and feedback from engaged educators.

* Keeping trend of what is going on. Helping others too and getting advices. All of them are very helpful.

Connections with peers, sharing ideas and knowledge

* It is a flexible arrangement, so I can get PD on-demand and request information from other library professionals in real time.

Any time I can learn something new, it is a benefit to my students/staff. I'm always looking for innovative ways to do things that will increase ethical use of technology, reading, and technology use in general.

* Easy access to like-minded professionals who offer support and collegiality that may not be available in face to face working environments. Many librarians work alone or are the only librarians in their school districts.

There aren't many local school librarians, so it provides a better professional community.

* Keeping one abreast of current development in the field of librarianship

It's instant, you can read it at a time convenient to you, it's current' you can get others' views quickly

* Making connections with school librarians throughout the world. Getting to know what their school libraries are like and how they operate. Supporting school librarianship in developing countries

Mixes work and pleasure, reliable format, allows for multi media to be shared easily

* I don't really like using facebook for professional things. I would much prefer to keep the two separate. I see my personal life and my life as a librarian as two different things and I really don't like mixing the two. But I am realising that I am in a minority with this opinion, and so I am trying to embrace it and have started subscribing to professional facebook groups. I still don't like it though and very rarely post anything!

Save time and money. Increase sharing ideas and news

* Access to the knowledge and ideas of others in the same role. I do not have a partner in my building.

You do not have to go separately to each one to check the posts. You can have everything on one spot.

* Learn from a diverse and knowledgeable group. Get perspectives from a multi-cultural group.

You get to hear from people all over the world and in diverse school settings.

* I feel like I connect with a more diverse group of people and that helps expand my ideas and way of thinking.

For schools like mine that have no or limited budgets, it's an alternative to workshops and classes that the school/employees can't afford to attend

* Good audience reach, fast responses possible, diverse users

Many of the people there are very passionate about their practice, and want to learn and share.

* I like the variety of answers from all over and the fact that I can get quick answers when I post something.

We have a solitary profession. We can be very isolated if we don't share with each other.

* It's an easy and efficient way to share information. Most people have FB accounts so it's widely accessible to most librarians.

It's current, you can embed content easily, asynchrous - so you can scan if you need to, you can tag your posts.

* Open forums, similar interests, growing your professional community, learning about educational trends in other states, bridging the gap between school and public librarians.

Working as a school librarian, you are usually the only one in your building. With Facebook, I have a huge group of librarians I can ask questions of, run ideas by, and learn from. I think it is a wonderful PLN.

* Having a bank of knowledge to go to for new ideas. Being able to read other postings and utilize that info at a later date.

Immediate Feedback, doesn't clog up my email, can check it when I have time, can block annoying users.

* Easy to network with overseas TL's; great sources of upcoming PD; easy platform to share photos/videos/information with colleagues and create a discussion.

It's a great source of inspiration and can help with advocating for changes in your school; and many other things!

* Sharing ideas, and seeing how other situations compare to mine

Partnering with and learning from other librarians is the best professional development out there.

* International perspective, crowdsourcing, motivational inspiration

It allows you to voice your opinion and share ideas.

* I have to say that I am enjoying this Facebook group so much. As librarians, we often work in isolation, and are not fully ap preciated by our administrators. My district terminated the library department coordinator 3 years ago, and we are now overseen by the director of technology and communications. Thank you for providing this valuable resource to all of us. 


\section{Challenges of Following Facebook Group(s) $(n=363)$ ?}

Despite the tremendous popularity of Facebook and Facebook group, 12.2\% of SLPs acknowledged that they do not use these venues for PD but rather for personal and family purposes. There were many varied reasons that some SLPs are not using the Facebook group as a PDT. This study reveals the main challenges of participating in a Facebook group as the lack of time $(56.2 \%)$ and the overwhelming number of posts $(43.8 \%)$ to read and explore. These challenges are not considered as obstacles or have very little effect on their participation in a Facebook group according to the majority of SLP respondents $(61 \%)$. Additionally, many practice sites have blocked employee access to social networking sites in an effort to prevent loss of productivity (Kukreja et al., 2011). This suggests that schools are still not willing to acknowledge this form of communication and CPD tool as legitimate, or they are fearful or they simply do not know how to manage it.

\section{CONCLUSIONS AND RECOMMENDATIONS}

Professional development is an essential activity for librarians of all types in their very practicebased field. Facebook group affords a platform that is free of charge for a diverse range of communities of practice and the time for librarians' CPD. Within the plethora of Facebook groups, thousands of SLPs create hundreds of discussion posts that address the spectrum of teaching and library management issues. Consequently, it is apparent that Facebook group is more than a social networking site, but a powerful medium for SLPs that can be utilized to enhance professional knowledge, teaching and research practice. The study might serve as a guidepost of present scenarios of school librarianship and the current and future professional learning trends in the school library profession. Future research on Facebook group focused on regional or country specific SLPs may provide clear and further understanding and the potentiality of Facebook group for professional development. Particular Facebook group posts, likes, comments and shares analysis would also be highly rational to learn the current and future trends in school librarianship. The author looks forward to extending his own understanding, networks and potential future collaborations of Facebook group.

The challenges associated with using the Facebook group for professional purposes can be overcome with a developed understanding of the tool and reference to professional guidelines. It is important to many professionals to maintain a professional distance from personal life so that they feel comfortable confiding in them and knowing that their information stays within context. In this case, Facebook group is worth considering to those who want or need to use social media for professional and personal situations as it differentiates among levels of access for friends, colleagues, and students through few privacy steps. Until the education community comes up with a formal means of professional development that is free, user-friendly, and timely, Facebook groups and similar forms of social media tools should be seen as an effective supplement to traditional professional development tools.

Consequently, creating specific user groups such as Elementary/Middle/High School Librarians/Teacher-Librarians/Media Specialist Facebook groups may develop strong and focused virtual informal professional development. Further, instead of dissuading librarians from joining Facebook and blocking access to similar social media sites, school administrators, and LIS associations and organizations should encourage and even support librarians' participation in these informative, efficient, and affordable professional development opportunities.

\section{REFERENCES}

ACRL (2000). ACRL Statement on Professional Development. Chicago, IL: American Library Association. Retrieved from http://www.ala.org/acrl/publications/whitepapers/acrlstatement

Ayu, A. R., \& Abrizah, A. (2011). Do you Facebook? Usage and applications of Facebook page among academic libraries in Malaysia. The International Information \& Library Review, 43(4), 239-249. 
Ballantyne, N., Lowe, S., \& Beddoe, L. (2017). To post or not to post? Perceptions of the use of a closed facebook group as a networked public space. Journal of Technology in Human Services, 35(1), 20-37.

Breeding, M. (2007). Librarians face online social networks. Computers in Libraries, 27(8), 30-33.

Charnigo, L., \& Barnett-Ellis, P. (2007). Checking out Facebook.com: The impact of a digital trend on academic libraries. Information technology and libraries, 26(1), 23.

Chen, Y. C. (2014). The effect of using a Facebook group as a learning management system. Computers in Education Journal, 5(4), 42-53.

Choi, C. (2012). Is your library ready for a Social Media Librarian? Paper presented in the Australian Library and Information Association Conference. Retrieved from http://conferences.alia.org.au/alia2012/Papers/18_Crystall.Choi.professional developmentf

Chu, S. K. W., \& Du, H. S. (2013). Social networking tools for academic libraries. Journal of librarianship and information science, 45(1), 64-75.

Curtis, D. (2011).What is social media? New Internet technologies are changing media. Retrieved February 27, 2013. $\quad$ Retrieved from http://www.uncp.edu/home/acurtis/Courses/ResourcesForCourses/SocialMediaWhatIsIt.html

Dickson, A., \& Holley, R. P. (2010). Social networking in academic libraries: the possibilities and the concerns. New library world, 111(11/12), 468-479.

Emery, J. (2008). All we do is chat: Social networking for the electronic resources librarian. Journal of Electronic Resources Librarianship, 20(4), 205-209.

Gruber, A. (2008). Wired professional development: New librarians connect through the web. College \& Undergraduate Libraries, 14(4), 95-102.

Graham, J., Faix, A., \& Hartman, L. (2009). Crashing the Facebook party: one library's experiences in the students' domain. Library Review, 58(3), 228-236.

Hagman, J., \& Carleton, J. (2014). Better together: Collaborating with students on library social media. Public Services Quarterly, 10(3), 238-244.

Hendrix, D., Chiarella, D., Hasman, L., Murphy, S., \&Zafron, M.L. (2009). Use of Facebook in academic health sciences libraries. Journal of the Medical Library Association, 97(1), 44-47.

Holmes, R. (2012, September 26). Universities are failing at teaching social media. CNN Money. Retrieved from http://tech.fortune.cnn. com/2012/09/26/universities-are-failing-at- teachingsocial-media/

Hossain, Z. (2016). Towards a lifelong learning society through reading promotion: Opportunities and challenges for libraries and community learning centres in Viet Nam. International Review of Education, 62(2), 205-219.

Karal, H., Kokoc, M., \& Cakir, O. (2015). Impact of the educational use of Facebook group on the high school students' proper usage of language. Education and Information Technologies, 1-19.

Kukreja, P., Heck Sheehan, A., \& Riggins, J. (2011). Use of social media by pharmacy preceptors. American journal of pharmaceutical education, 75(9), 176. Retrieved from http://pubmedcentralcanada.ca/pmcc/articles/PMC3230337/professional developmentf/ajpe759176.professional developmentf

Lin, N. (2002). Social capital: A theory of social structure and action. New York, NY: Cambridge University Press.

Majid, S. (2004). Continuing professional development (CPD) activities organized by library and information study programs in Southeast Asia. Journal of Education for Library and Information Science, 45(1), 58-70

Manca, S., \& Ranieri, M. (2013). Is it a tool suitable for learning? A critical review of the literature on Facebook as a technology-enhanced learning environment. Journal of Computer Assisted Learning, 29(6), 487-504.

Mathews, B. S. (2006). Do you Facebook?: Networking with students online. C\&RL News, 67( 5), 306307. 
Mattingly T., Cain J., \& Fink J. (2010). Pharmacists on Facebook: Online social networking and the profession. Journal of the American Pharmaceutical Association, 50(3), 424-427.

McCallum, Ian. (2015). Use of social media by the library: Current practices and future opportunities. $A$ White Paper from Taylor \& Francis, 161-162.

McKenzie , D. (2015, Dec. 15). Getting social, media. Library Grits. Retrieved from http://librarygrits.blogspot.com/2015/12/getting-social-media.html

McKenzie , D. (2016, Nov. 23). Facebook groups supporting professional learning. Library Grits. Retrieved from http://librarygrits.blogspot.com/2016/11/facebook-groups-supportingprofessional.html

Meyrowitz, J. (1997). Shifting worlds of strangers: medium theory and changes in "them" versus "us". Sociological Inquiry, 67(1), 59-71.

Onuoha, U. D. (2013). Librarians' use of social media for professional development in Nigeria. Information Management and Business Review, 5(3), 136. Retrieved from https://professional developmentfs.semanticscholar.org/9c23/ 1e4b973aa8bd20ad64610c49d208f73cbc73. professional developmentf

Parveen, N. (2011). Use of social networking site (Facebook) in making awareness among the library and information science professionals of university libraries of U.P: a case study. International Journal of Digital Library Services, 1(1), 9-17.

Ramsey, E., \& Vecchione, A. (2014). Engaging library users through a social media strategy. Journal of Library Innovation, 5(2), $\quad 71 . \quad$ Retrieved from http://citeseerx.ist.psu.edu/viewdoc/download?doi=10.1.1.679.6263\&rep=rep1\&type=professiona 1 developmentf

Ranieri, M., Manca, S., \& Fini, A. (2012). Why (and how) do teachers engage in social networks? An exploratory study of professional use of Facebook and its implications for lifelong learning. British Journal of Educational Technology, 43(5), 754-769.

Simons, R. N., Ocepek, M. G., \& Barker, L. J. (2016). Teaching tweeting: Recommendations for teaching social media work in LIS and MSIS Programs. Journal of Education for Library and Information Science, 57(1), 21.

Suraweere, S. A. D. H. N., et al (2011). Value of social Networking in Libraries and Information Organization in Asia and Oceania. World Library and Information Congress: 76th IFLA General Conference and Assembly. 10-15 Aug 2010, Gothenberg, Sweden..

Vassilakaki, E., \& Garoufallou, E. (2015). Library Facebook practices for creating and promoting a professional profile. Program, 49(3), 343-359.

Wang, Q., Woo, H. L., Quek, C. L., Yang, Y., \& Liu, M. (2012). Using the Facebook group as a learning management system: An exploratory study. British Journal of Educational Technology, 43(3), 428-438.

Wassen, H. (2016). Professional development on Facebook. Retrieved from https://www.kau.se/en/matematik/research/forskningsprojekt/professional-development-facebook

Young, S. W. H., and Rossmann, D. (2015). Building Library Community Through Social Media. Information Technology and Libraries, 34(1), 20-37. 